\title{
An Empirical Assessment of Public Policy Communications in Central Region of Vietnam
}

\author{
Huynh Quy, Thai Thanh Ha \\ National Academy of Public Administration (NAPA), Hanoi, Vietnam \\ Email: huynhquyqnam@gmail.com, thaiha63@napa.vn
}

How to cite this paper: Quy, $\mathrm{H}$. and $\mathrm{Ha}$, T.T. (2018) An Empirical Assessment of Public Policy Communications in Central Region of Vietnam. Modern Economy, 9, 2052-2063.

https://doi.org/10.4236/me.2018.912128

Received: November 2, 2018

Accepted: December 10, 2018

Published: December 13, 2018

Copyright $\odot 2018$ by authors and Scientific Research Publishing Inc. This work is licensed under the Creative Commons Attribution International License (CC BY 4.0).

http://creativecommons.org/licenses/by/4.0/

(c) (i) Open Access

\begin{abstract}
Communication is the object of policy, as witnessed in the efforts by government and non-government agencies to inform and educate various publics about problems in society. Effective public policy communications are an important tool to help achieve the policy's objectives. It is imperative that transparency and proactive public policy communications continue to be the anchors of the current working agenda in most of developing countries' government. The public policy communications in Central Region of Vietnam have been characterized by unpredictable patterns of policy adoption, the geographical distance, and the economic disparity as compared to the capital city of Hanoi. To fill in this academic gap, this paper identified the factors that consist of the public policy communication on the basis of literature review. The conceptual framework was developed and revised in order to lay the theoretical grounds. Based on this, questionnaire was developed for data collection in major locations in Central Vietnam. Multivariate data analysis techniques such as Exploratory Factor Analysis (EFA) and multiple regressions were used to gauge the impacts of possible factors on the public policy communication as perceived from citizen-level perspective in Central Vietnam. Recommendations and implications were drawn to strengthen public policy communication strategies in Central region of Vietnam.
\end{abstract}

\section{Keywords}

Public Policy, Communication Strategies, Central Region of Vietnam

\section{Introduction}

Communication plays an important role in all aspects of the development and use of public policy [1]. Being a linkage between the government and its citizen, an effective communication is critical for the success of putting public policies 
into practice [2]. Previous works in policy diffusion research boil down to the fact that effective communication strategies are essential prerequisites for executing the public policy as motivating, persuading, and information-sharing are the basic functions of communication strategies [3]. The government communication strategies have been greatly examined by a large number of scholars, whose results have been discussed in great deal of studies [4] [5]. However, these studies have seemingly put its focus on the firms' adoption of public policy while neglecting to take into account the public policy diffusion process from citizen-level perspective [6].

In Vietnam law-makers have been discussing hotly the public policy process during National Assembly's working sessions, which is to be televised to the nation-wise public, the effectiveness and efficiency of public policy communications seems to be left open. This status-quo is challenging for local governments in Central region of Vietnam which is economically and geographically marginalized as compared to cities of Hanoi or Ho Chi Minh. Coupled with the fact that the public policy is often communicated with a mixed approach, the ultimate adoption patterns are not paid sufficient attention in most cases. Therefore, the voices from citizen may not be heard of, or their perspective might be neglected. While rhetoric is made in qualitative form, empirically testing the causal relationship between government communication strategies and citizen's public policy adoption behavior is rare in Central region of Vietnam. Filling the gap is urgent both practically and academically.

In this paper, we utilized the conceptual framework previously developed on the basis of categorizing the communication into key features that several scholars have discussed [7]. It is essential to capture the citizen's attitude toward the government's communication strategies; therefore, the psychological reactance is used. As the goal of communicating public policies is to change the citizen's behavior, this paper also finds it necessary for citizen to accurately perceive the communication strategies that the government pursues. Their perception would serve as feedback for the public policy makers, in a later stage, to design effective communication strategies in such a way that they would encourage active adoptions while controlling the opportunistic adoption behavior in Central region of Vietnam.

\section{Conceptual Framework on Public Policy Communications}

Some public policies are swiftly adopted while some delays often occur for the other policies to be put into implementation. In general, they have been categorized as two types of government public policies depending on their attributes [7] [8]. The former ones are labeled as the preferred policies which imply the quickly taken policies. The latter ones are considered as non-preferred polices. The deficiency of discussions on effective policy implementation particularly for non-preferred policies, which has an innate problem of slow diffusion, should be one of the main research focuses [7] [9]. However, government's intervention with intention to instigate the fast adoption of the non-preferred public policy 
often leads to the conflict among concerned parties [10]. If governments impose their political will on its citizen and force them to adopt the non-preferred public policies without properly communicating the intention and the need, concerned parties may become more hesitant toward adopting these policies [7] [11]. Therefore, this attitude is classified to fit very well into the concept of psychological reactance [1] [12]. The reactance theory postulates that when an individual is being compelled by an authority, one would have a feeling that his or her flexibility or discretion has been threatened or deprived, leading to the psychologically discontent status. This would give rise to the psychological reactance. In a more practical sense, it would take the forms of reluctance, compliance, doubts and complaints [13]. Figure 1 depicts the conceptual framework for our research.

The flow of information, or the direction represents the extent to which the communication can be a one-way or two-way between the two parties of communication: the government and its citizen [7]. One-way communication is concerned with spreading information only from the government to citizen. Two-way communication entails a mutual exchange of information where citizen can share problems or suggest opinions with the government upon adopting the policy. Recently, public sector organizations have resorted to the Internet homepages or even personified blogs to promote the citizen participation in the communication with them. Such two-way communication allows for the mutual understanding of each other's needs and wants from both sides. Since a new policy requires a learning phase, interactive learning is an important factor in the policy adoption [13].

Government intervention with an intention to institute fast adoption of the non-preferred public policies often causes conflict between the government and individuals in the communication. This attitude could be explained by applying the concept of psychological reactance which should be grouped into such attitudinal patterns as; carefulness toward other's advice; and avoidance of conflict;

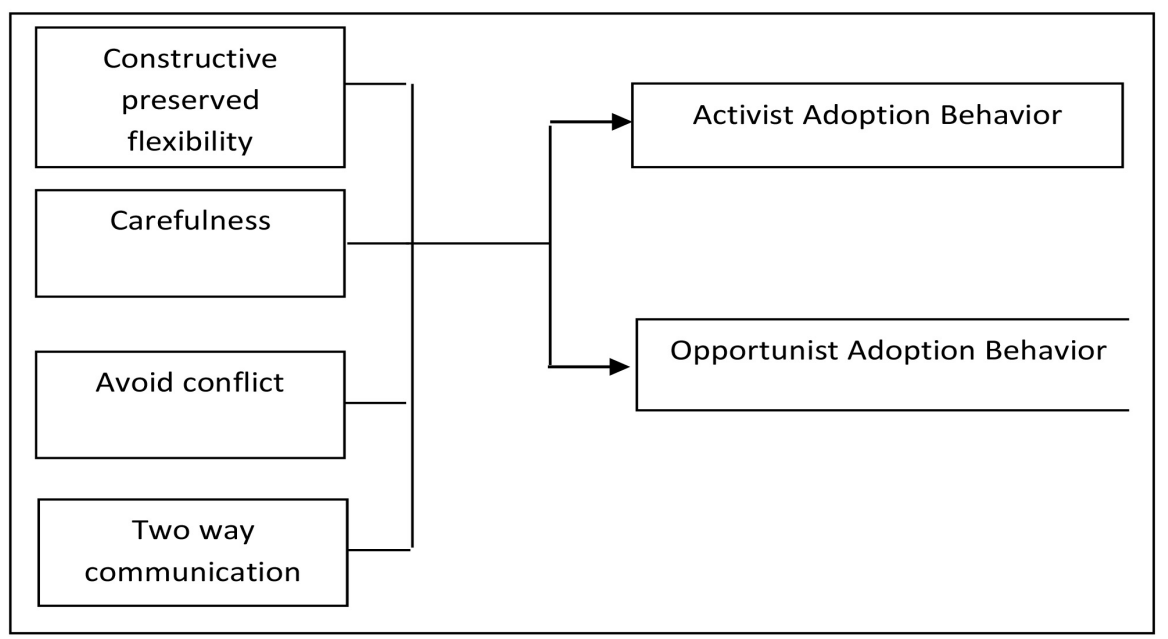

Figure 1. Proposed conceptual framework. 
flexibility in decision and behavior [7] [13] [14]. The carefulness and reactance towards advice and recommendations suggest an individual's disbelief of advice and negligence of recommendations from others. Avoidance of conflict is an individual's tendency to go along with others and avoid disagreements, as one of the attitudinal patterns of the psychological reactance [14]. Constructive preserved flexibility is the attitudinal reactance towards being dependent and preservation of flexibility of individuals. All of these things are composed of an individual's desire to state their opinion and to have things in line with his or her beliefs. In case, the non-preferred public policy is an unavoidable reality, citizen often have a desire to state their opinion to the government and mend the policy to fit their needs as much as possible. This attitudinal pattern falls under the positive attitude [7] [14].

In the proposed conceptual framework, we identified true adoption of non-preferred public policy by distinguishing the adoption behavior into "active adoption" and "opportunistic adoption". First, the active adoption entails individual's behavior or culture of voluntarily adopting the non-preferred public policies. Second, the opportunistic adoption also is likely to be influenced by both the positive and negative adoption individual's attitudes. Positive adoption attitudes are more likely to be negatively inclined while negative adoption attitudes are more likely to be positively inclined toward opportunistic adoption behaviors. These two public policy adoptions are explored with the causal relationships in our empirical study.

\section{Research Methods}

\subsection{Measurement of Constructs}

We used the constructs theoretically based on the comprehensive review of the literature [1]-[9] [15]. These constructs are modified to have the advantage of the validity of existing research and to take into consideration of the country's status quo with regards to the communicating of the public policies. To work on the measurement items, we adopted and modified the constructs for the communication of public policies with regards to two-way, symmetrical, and ethical communication variables. The interpersonal pattern is not consulted due to its similarity with the two-way communication attribute in order to avoid the unexpected replication. To gauge the citizen's attitudes towards the public policies which shape the two patterns as described in the literature, we found it necessary to modify the measurement items referred to the studies of several scholars [7] [16] in order to fit the purpose of our study. Lastly, item measuring the activist adoption and opportunist adoption were taken from the previous study because of it validity and reliability [7] [17]. The total measurements resulted in a total number of 26 items which we used to develop our self-administered questionnaire for the information gathering phase.

\subsection{Data Collection}

To collect the data, a version of self-administered questionnaire using five-point 
Likert scale, with anchors ranging from strongly disagree $(=1)$ to strongly agree $(=5)$, was developed and followed up in the field survey. We used the back-translation techniques to ensure the semantically equal contents. That is, it was first designed on the basis of the conceptual framework with above mentioned 26 items semantically developed in English. It was then translated into Vietnamese by a bilingual researcher. Another different bilingual counterpart translated the questionnaires back into English for the comparison of the original version and the newly back-translated one. This was conducted because most of the instrumentation had been designed in the West, and evidence of cross-cultural validity of the variable operationalization was scant [17]. To verify the accuracy and quality of the translations, pre-tests using both the original and translated version were conducted on two bilingual respondents [7] [17] [18]. The results showed that both Vietnamese and English versions of questionnaire produced the same pattern of responses, confirming that the translated questionnaires were sufficiently reliable [18].

When it comes to data collection for empirical studies, researchers usually face a number of obstacles, including the inefficiencies and undependability of the postal system [17] [19]. Therefore, field data collectors were trained to conduct face-to-face interview. With this, the aim of the research was explained in detail or in case questions may need clarification. Self-administered questionnaires were given to the respondents to fill in. Data were gathered from a number of citizens, public officers currently working in municipalities' jurisdictions in Central region of Vietnam. This resulted in 254 completed and usable questionnaires which are sufficient to conduct exploratory factor analysis as decribed in a later stage [18].

\subsection{Analysis and Findings}

We coded collected field survey data into the IBM SPSS Statistics version 20 for further multivariate data processing and analysis. We performed the data validation and cross-examination for accuracy in our study. Missing values otherwise not practically being validated must also be replaced with mean series techniques [18]. We performed the multivariate data analysis in sequential stages. Firstly, data were factor analyzed to condense them into desirable variables due to the exploratory nature of this paper. Secondly, multiple regressions were run to test the strength of causal relationships among variables according to the conceptual framework by looking at the $\mathrm{R}^{2}$ as well as Beta coefficients equivalent to respective variables. Thirdly, we compared the two types of policy adoption behaviors by looking at the respective standardized Beta coefficients of each corresponding behavioral patterns.

Table 1 presents the demographics of the sample. Total respondents of 254 were equally distributed in terms of male (50.6 percent) and female (49.4 percent) in the sample. The respondents ranged from 30 to 50 years of age brackets with a cumulative percentage of $71.2 \%$. Female respondents were $128(50.6 \%)$ while male percentage accounted for $49.4 \%$ (125). Types of profession indicated 
Table 1. Demographics of the respondents.

\begin{tabular}{|c|c|c|c|c|c|}
\hline Gender & $\mathrm{N}$ & $\%$ & Types of Professions & $\mathrm{N}$ & $\%$ \\
\hline Female & 128 & 50.6 & Managers & 24 & 9.5 \\
\hline Male & 125 & 49.4 & Civil servants & 169 & 66.8 \\
\hline Total & 253 & 100 & Small vendors & 7 & 2.8 \\
\hline Public policy insight & $\mathrm{N}$ & $\%$ & Small traders & 3 & 1.2 \\
\hline Newspaper & 18 & 7.1 & Housekeepers & 3 & 1.2 \\
\hline E-newspapers & 98 & 38.7 & Employees in private sector & 5 & 2.0 \\
\hline News program on $\mathrm{TV}$ & 92 & 36.4 & Employees in SOEs & 7 & 2.8 \\
\hline Office meetings & 29 & 11.5 & Students & 31 & 12.3 \\
\hline Talks with colleague & 8 & 3.2 & Others & 4 & 1.6 \\
\hline Words of mouth & 7 & 2.8 & Total & 253 & 100 \\
\hline Other forms & 1 & 0.4 & \multirow{2}{*}{ Ages } & \multirow{2}{*}{$\mathrm{N}$} & \multirow{2}{*}{$\%$} \\
\hline Total & 253 & 100 & & & \\
\hline Degree of involvement & $\mathrm{N}$ & $\%$ & Below 30 & 83 & 33.2 \\
\hline Directly & 8 & 30.8 & In $30-40$ years old & 111 & 44.4 \\
\hline Indirectly & 17 & 65.4 & In 40 - 50 years old & 42 & 16.8 \\
\hline Others & 1 & 3.8 & Above 50 years old & 14 & 5.6 \\
\hline Total & 26 & 100 & Total & 250 & 100 \\
\hline
\end{tabular}

Source: data analysis from the field survey 2017.

that a large proportion was accrued to the civil servants with $66.8 \%$ (169) as well as students with $12.3 \%$. The popular sources of information were mainly e-newspapers and TV news program. Degree of involvement was mainly associated with managers with $9.5 \%$ of the sample.

We used exploratory factor analysis (EFA) to condense the data into confirmed variables. Factor loadings of 0.5 or larger must be the cut-off point to retain the item on the rotated factor [18]. To perform EFA, a sample size must be sufficient as required by the nature of this quantitative paper on the rule-of-thumb condition 5 to 1 . In this research the number of completed and usable self-administered questionnaires amounted to 254 from the field survey which surpassed the number of 26 item statements. On top of this, the Kaiser-Meyer-Olkin (KMO) test resulted in a value of 0.89 . This test value was acceptable and close to the 0.9 level, indicating the confirmation of sampling adequacy for factor analysis [18].

Table 2 presents the EFA results. The six-factor solution was obtained on the basis of Eigen value values greater than 1.0, factor loadings above the cut-off threshold of 0.3 , and total variance explained approximately $62 \%$. The average scores of these items which were loaded on these factors were used to create the required six variables for further analysis on a later stage. The Cronbach Alpha reliability values for these six subsequent factors were acceptable [18]. 
Table 2. Exploratory factor analysis.

\begin{tabular}{|c|c|c|c|c|c|c|}
\hline \multirow{2}{*}{ Item statements } & \multicolumn{6}{|c|}{ Factors } \\
\hline & 1 & 2 & 3 & 4 & 5 & 6 \\
\hline 1) Opinions are exchanged & 0.79 & & & & & \\
\hline 2) Carefully consider benefits and harms & 0.79 & & & & & \\
\hline 3) Suggestions from are taken for policies & 0.79 & & & & & \\
\hline 4) Mutual trusts are built & 0.78 & & & & & \\
\hline 5) Thorough research prior to policies & 0.75 & & & & & \\
\hline 6) Reduce misunderstanding & 0.75 & & & & & \\
\hline 7) Increase understanding of public policies & 0.73 & & & & & \\
\hline 8) Motives are explained & 0.64 & & & & & \\
\hline 9) Influences are made aware & 0.50 & & & & & \\
\hline 10) Not wish to be in conflict & & 0.88 & & & & \\
\hline 11) Not wish to be stressed & & 0.84 & & & & \\
\hline 12) Not wish to get penalties & & 0.76 & & & & \\
\hline 13) Not understand the necessity & & & 0.85 & & & \\
\hline 14) Find it difficult to adopt & & & 0.80 & & & \\
\hline 15) Really trouble when to fulfill & & & 0.63 & & & \\
\hline 16) Will be blamed if caught non-compliant & & & & 0.77 & & \\
\hline 17) Not wish to be imposed upon & & & & 0.69 & & \\
\hline 18) To be in doubt with scandal & & & & 0.65 & & \\
\hline 19) Corrective measures must be in place first & & & & 0.50 & & \\
\hline 20) Public policies come first & & & & & 0.74 & \\
\hline 21) Sufficient condition upon implementation & & & & & 0.69 & \\
\hline 22) Citizen are ready to encourage others & & & & & 0.58 & \\
\hline 23) Comparing with each other are normal & & & & & 0.50 & \\
\hline 24) Actively let the difficulties be known & & & & & & 0.77 \\
\hline 25) Change to be made to suit to circumstances. & & & & & & 0.63 \\
\hline 26) Questions are made regarding public policies & & & & & & 0.59 \\
\hline Cronbach Alpha reliability & 0.84 & 0.84 & 0.78 & 0.78 & 0.63 & 0.73 \\
\hline Cumulative variance explained & $27.4 \%$ & $41.4 \%$ & $48.1 \%$ & $53.2 \%$ & $58.0 \%$ & $62 \%$ \\
\hline
\end{tabular}

Source: data analysis from the field survey 2017.

Factor \# 1 is labeled as two way communication. It possesses loaded items which measure a wide range of activities such as taking the citizens' suggestions regarding the public policies; exchange of opinion with them on regular bases; weighing the benefits and harms upon citizens that the resulting public policies may have so on and so forth. The factor was named as two-way communications because of its largest factor-loading which is concerned with the fact that opi- 
nions are exchanged between the government and citizens.

By the same token, factor \# 2 was labeled as avoid conflict. It measures the extent to which this newly created dimension is concerned with the fact that citizens are not in favor of undertaking penalties, being stressed with the authorities over non-compliance to public policies, or conflicting with the authorities for not comforting the public polices. In case of a transitional society like Vietnam, this attitudinal pattern is very an important stepping stone for the public policy adoption behaviors that follow.

The similar reasoning also leads to the naming of factor \# 3 as Carefulness. This newly created factor reflects an attitudinally important pattern which belongs to the psychological reactance. The individual citizen's tendency is to state their opinion to the government and wishes to mend the public policy to fit their need as much as possible [7] [14].

The fourth factor is named as Constructive Preserved Flexibility. The loaded items for this factor indicate the constructive preserved flexibility and expresses the citizen's desire to offer his or her constructive opinion with regards to the public policy communication strategies. The nature of this type of attitudinal pattern would likely lead to the positive attitude. It, in turn, has a high propensity to bring about the citizens' positive adoption behavior towards the public policy [14].

The last two factors are the end results of the government's policy diffusion which are interpreted as dependent variables of activist behavior and opportunist behaviors [7] [13] [14]. The former one is composed of four loaded items which range from such government's activities as imposition of the public policies upon them by the authorities; or troubling sentiments instigated by the government's request to fulfill any single details of the public policies; or the lack of sufficient conditions to accomplish their duties and so on. The latter one also consists of three items. It refers to the opportunist behavior of the citizens is strongly correlated to the nature of wishing to avoid the government intervention or control [7]. Superficially, non-preferred public policies seem to be a misleading reason to ignite the citizens' aversions to this type of policy in the first place. However, they may still display active adoption behavior just simply to obtain incentives and benefits from the government or concerned authorities [7] [18]. The two newly created factors, therefore, should be looked examined with causal relationship, between the government communication strategies and public policy adoption attitudes in the next paragraphs. These six newly created factors were created in the database by taking the average scores of the items identified by factor analyzing. They would be used in the multiple regression analysis as described below.

The results of causal relationships are shown in Table 3. The four independent predictors of Two way communication $\left(X_{1}\right)$; Avoid Conflict $\left(X_{2}\right)$; Carefulness $\left(X_{3}\right)$ and Constructive Preserved Flexibility $\left(X_{4}\right)$ are regressed against two policy adoption behaviors $\left(Y_{1}=\right.$ Opportunist behavior; and $Y_{2}=$ Activist behavior). The standardized beta coefficients for these four predictors were positively 
Table 3. Multiple Regression Analysis of public policy communication strategies.

\begin{tabular}{|c|c|c|c|c|}
\hline \multirow{2}{*}{ Predictors } & \multicolumn{2}{|c|}{$Y_{1}$. Opportunist behaviour } & \multicolumn{2}{|c|}{$Y_{2}$. Activist behaviour } \\
\hline & Std Beta & VIF & Std Beta & VIF \\
\hline Gender: Male $=1 ;$ Female $=0$ & $0.08^{*}$ & 1.04 & $\underline{0.12^{* \star}}$ & 1.04 \\
\hline$X_{1}$ : Two way communication & $0.15^{\star \star}$ & 1.15 & $\underline{0.50}^{* * *}$ & 1.15 \\
\hline$X_{2}$ : Avoid conflict & $\underline{0.29} \underline{4 * *}^{* *}$ & 1.18 & $0.12^{\star}$ & 1.18 \\
\hline$X_{3}$ : Carefulness & $\underline{0.33^{* * *}}$ & 1.12 & $0.19^{\star * *}$ & 1.12 \\
\hline$X_{4}$ : Constructive Preserved Flexibility & $\underline{0.18}^{\star * *}$ & 1.27 & $0.13^{*}$ & 1.27 \\
\hline $\mathrm{R}^{2}$ & \multicolumn{2}{|c|}{0.59} & \multicolumn{2}{|c|}{0.64} \\
\hline ANOVA & & & \multicolumn{2}{|c|}{$\begin{array}{c}F \text { test }=37.2 \\
\text { Sig at } 0.00\end{array}$} \\
\hline
\end{tabular}

Source: data analysis from the field survey 2017.

correlated with both Opportunist behavior and Activist behavior of public policy adoption.

Gender was coded as the dummy variable with male respondents being considered as the reference group in an effort to assess the impact of policy communication strategies of the government and citizen's attitudinal patterns on the adoption behaviors. The R squares and ANOVA tests indicated a reasonable degree of robustness for both multiple linear regression models. Examination of the variance inflation factor (VIF) for all variables indicated that these VFI figures fell below the cut-off threshold of 10, as suggested by Hair et al. [18], confirming that there was no multi-collinearity and the required assumptions for the linear regressions were assured [17] [18].

For comparison, Standardized Beta coefficient of Two-way communication in the Activist behavior model was larger than that of Opportunist behavior model (0.5 versus 0.15). Further examination of standardized beta coefficients for gender dummy variable led to the conclusion that male respondents are more positively inclined to both Activist and Opportunist behaviors as compared to their female peers. The absolute value of standardized Beta coefficients for Activist behavior was exceeding that for Opportunist behavior, thus, indicating a stronger impact for the active adoption behavior pattern on the part of male respondents ( 0.12 versus 0.08$)$.

For Opportunist behavior model, the standardized Beta coefficients of Avoid conflict (0.29); Carefulness (0.33); and Constructive preserved flexibility (0.18) were positively larger than those for Activist Behavior model respectively of 0.12; and 0.19 and 0.13 . The comparison indicated the stronger impacts of these predictors on the opportunist behavior pattern than the active behavior adopter.

\section{Implications}

Looking back to two decades ago, no one could have dreamt of the on-going reality of the public policy communications in Central region of Vietnam [19] [20] 
[21]. Vietnamese citizen are allowed to be aware of day-to-day works of the government, kept informed of the trials of corrupted high-ranking officials; or invited to give comments on the long-term visionary plans as to the socio-economic development of the country. Yet, the empirical evidence concerning public policy communication strategies is limited in helping to explain the results. Therefore, the political and legislative dimensions of public policy communication patterns may be a related factor for confusing attitudinal adoptions [22] [23].

In Central region of Vietnam, communicating public policies is referred to as propaganda or the propagating of state-issued policies or legislations to the people [24]. In struggling with vested interests that survive by nepotism and corruption, Central Vietnam's public policy communication strategy has been used, most often than not, as a means to unfold the anti-corruption fighting behind the Central government's political reform [20] [23] [24]. In this course of action, media are used as communicating tools to critically stir up the public opinion first, then launch the public policy communication to fight against the society's criminals on the motto: "everyone is equal before the laws", or "there is no trespassing zone for any one" [20] [23] [25]. The city of Da Nang, once hailed as being worth of living, have been rifted by several governance mistakes, and exposed to a number of administrative scandals, thanks largely to the effective two-way communication between the authorities and citizen.

There are several limitations that need to be pointed out in our study. First, the exploratory findings need to be considered tentatively, even though its is interesting because there are very few empirical studies to enrich our understanding of this complex matter. The generalizability of the proposed conceptual framework for assessing the communicating of public policies, especially in Central region of Vietnam context, however, should be taken with due care. On the one hand, this paper relies on purposive sampling rather than a more scientifically, suitable sample. On the other hand, the nature of exploratory factor analysis would not ensure the desirable number of loaded items on the contruct as identified in the conceptual framework. The sampling composition and quantity was conformed to only several locations in Central region of Vietnam. Therefore, it needs to be enlarged on a nation-wide scale in order to have a broader picture. There is a plenty of room for future research in which confirmatory factor analysis should be adopted with the aim to confirm the validity of the latent and observed variables as conducted in the study of Kang et al. [7] for assessment of communication strategies of public policies. Several specific public policies such as health care, insurance policies, downsizing can be explored to get better understanding on the burning issues in the publicpolicy communicating process in Vietnam in general, and in Central region in particular.

\section{Conflicts of Interest}

The authors declare no conflicts of interest regarding the publication of this paper. 


\section{References}

[1] Zhang, Y.L and Zhu, X.Y (2017) Multiple Mechanisms of Policy Diffusion in China. Public Management Review.

[2] ADB (2011) Public Communication Policy 2011: Disclosure and Exchange of Information. SBN 978-92-9092-483-8, Publication Stock No. RPT114096.

[3] Bender, K. and Keller, S. (2014) The Role of International Policy Transfer and Diffusion for Policy Change in Social Protection: A Review of the State of the Art. IZNE Social Protection Working Paper 14/1, International Policy Learning and Policy Change: Scientific Inputs for the Dialogue on Social Protection with Global Partners.

[4] Klijn, E.H. and Korthagen, I. (2017) Governance and Media Attention: A Research Agenda about How Media Affect (Network) Governance Process. Perspective on Public Management, 1, 103-113. https://doi.org/10.1093/ppmgov/gvx004

[5] Boushey, G. (2010) Policy Diffusion Dynamics in America. Cambridge University Press, Cambridge. https://doi.org/10.1017/CBO9780511778834

[6] Hoa, T. and Zamour, J.C.G. (2017) Citizen Participation in Vietnam's Local government: Impact on Transparency and Accountability. International Journal of Public Administration and Governance, 7, 38-57.

https://doi.org/10.5296/jpag.v7i4.12044

[7] Kang, I., Lee, G., Park, C. and Shin, M. (2013) Tailored and Targeted Communication Strategies for Encouraging Voluntary Adoption of Non-Preferred Public Policy. Technological Forecasting \& Social Change, 80, 24-37. https://doi.org/10.1016/j.techfore.2012.08.001

[8] Graham, E., Shipan, C. and Volden, C. (2013) The Diffusion of Policy Diffusion Research in Political Science. British Journal of Political Science, 43, 673-701. https://doi.org/10.1017/S0007123412000415

[9] Vasavakul, T., Le, T. and Le, V. (2009) Public Administration and Economic Development in Viet Nam: Reforming the Public Administration for the 21st Century. Reforming Public Administration in Viet Nam, 41.

[10] LeGreco, M. and Heather, E.C. (2011) Enacting Sustainable School-Based Health Initiatives: A Communication-Centered Approach to Policy and Practice. American Journal of Public Health, 3, 431-437. https://doi.org/10.2105/AJPH.2009.186858

[11] Huang C., Yue, X.X., Yang, M.Q., Su, J. and Chen, J. (2017) A Quantitative Study on the Diffusion of Public Policy in China: Evidence from the S\&T Finance Sector. Journal of Chinese Governance, 3, 235-254. https://doi.org/10.1080/23812346.2017.1342381

[12] Dowd, E.T., Milne, C.R. and Wise, S. (1991) the Therapeutic Reactance Scale: A Measure of Psychological Reactance. Journal of Counseling and Development, 69, 541-545. https://doi.org/10.1002/j.1556-6676.1991.tb02638.x

[13] Hong, S.M. and Ostini, R. (1989)Further Evaluation of Merz's Psychological Reactance Scale. Psychological Review, 64, 707-710.

[14] Buboltz Jr., W., Thomas, A. and Donnell, A. (2002) Evaluating the Factor Structure and Internal Consistency Reliability of the Therapeutic Reactance Scale. Journal of Counseling and Development. 80, 120-125. https://doi.org/10.1002/j.1556-6678.2002.tb00174.x

[15] Yun, S.H. (2006) Toward Public Relations Theory-Based Study of Public Diplomacy: Testing the Applicability of the Excellence Study. Journal of Public Relation, 18, 287-312. https://doi.org/10.1207/s1532754xjprr1804_1 
[16] Howlett, M. (2009) Government Communications as a Policy Tool: A Framework for Analysis. The Canadian Political Sciences Review, 6, 23-37. https://ojs.unbc.ca/index.php/cpsr/article/view/134/184

[17] Swierczek, W. and Ha, T.T. (2003) Entrepreneurial Orientation, Uncertainty Avoidance and Firm Performance. International Journal of Entrepreneurship and Innovation, 4, 46-58. https://doi.org/10.5367/000000003101299393

[18] Hair, et al. (2007) Multivariate Data Analysis. McGraw Hill Publishing, New York.

[19] Government of Vietnam (2013) Decree on Detailing Articles and Measures to Implement the Laws No. 14/2012/QH13.

[20] Atshushi, T. (2017) Power Struggle Unfolds Behind Vietnam's State Reforms. Nikki Asian Review.

[21] Alsaghier, H., Ford, M., Nguyen, A. and Hexel, R. (2009) Conceptualizing Citizen's Trust in e-Government: Application of Q Methodology. Electronic Journal of e-Government, 4, 295-310. http://www.ejeg.com

[22] Desmarais, B.A., Harden, J. and Boehmke, F.J. (2015) Persistent Policy Pathways: Inferring Diffusion Networks in the American States. American Political Science Review, 109, 392-406. https://doi.org/10.1017/S0003055415000040

[23] Phuong, T. (2017) Vaitrocuatruyen thong chinhsach de manglaisu dong thuanxa hoi. The 201 st International Conference on Communicating Public Policies: Experiences of Vietnam and Korea, Ha Noi, 1 November 2017.

[24] Lim, G. (2017) Public Policy with Vietnamese Characteristics: The Case of Motorcycle Industry. Journal of Asian Public Policy, 11, 1-19.

[25] National Assembly (2012) Laws on Propagating and Educating Legal Legislations. Laws No. 14/2012/QH13. 